\title{
The Corbridge Excavations, 1907
}

\section{R. H. Forster}

To cite this article: R. H. Forster (1908) The Corbridge Excavations, 1907, Archaeological Journal, 65:1, 121-123, DOI: 10.1080/00665983.1908.10853080

To link to this article: http://dx.doi.org/10.1080/00665983.1908.10853080

$$
\text { 曲 Published online: } 17 \text { Jul } 2014 .
$$

Submit your article to this journal

LII Article views: 3

Q View related articles $\asymp$ 


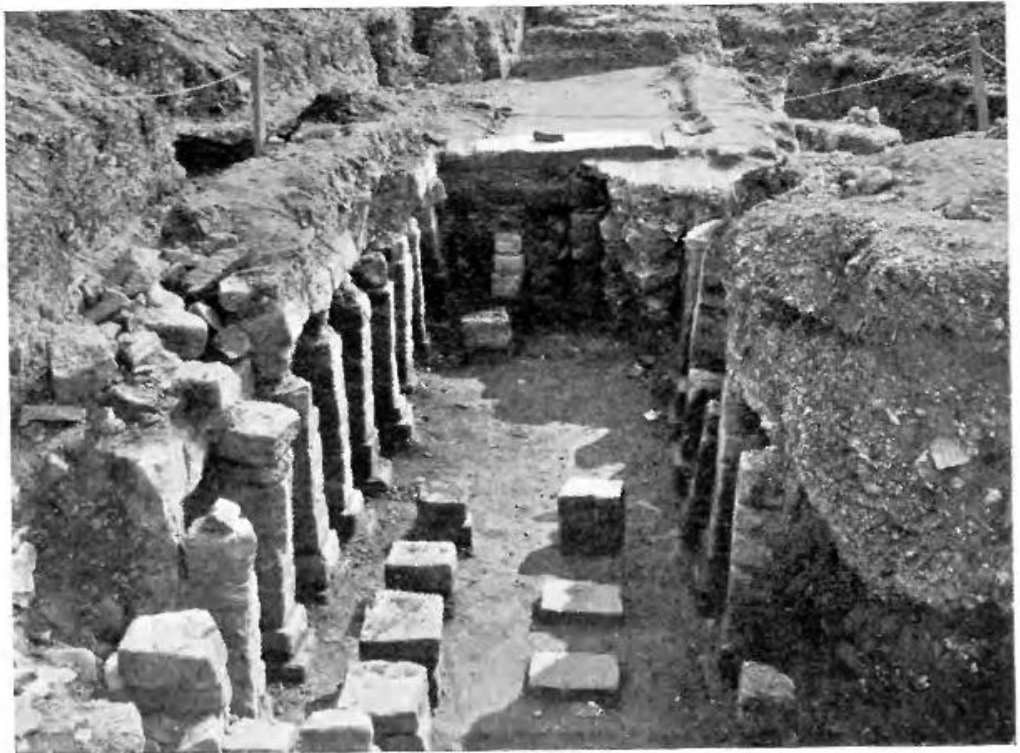

FIG, 1.-REMAINS OF PILI.ARED HYPOCATST.

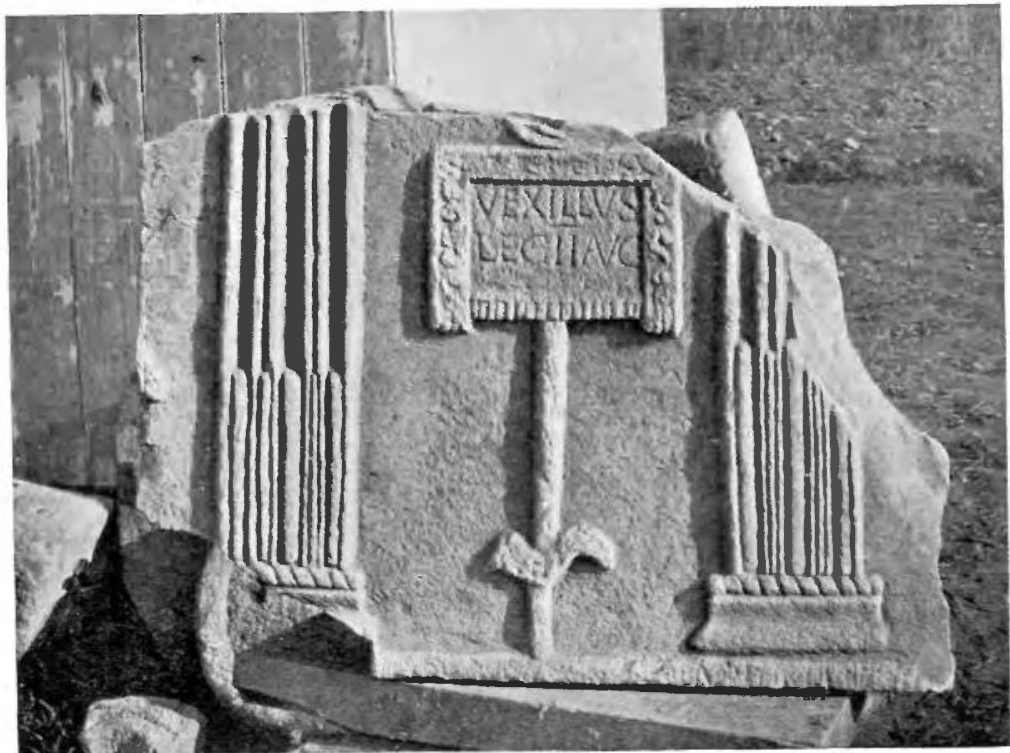

FIG. 2.-SLAB TITH REPRESENTATION OF A LEGIONART STANDARD. 


\section{THE CORBRIDGE EXCAVATIONS, 1907.}

By R. H. FORSTER.

These excavations were continued from July to October, 1907, under the superintendence of Mr. C. L. Woolley, M.A., with satisfactory results. A portion of the main road to the town from the south, close to the site of the northern abutment of the bridge, was carefully examined, remains of three distinct periods being found. As elsewhere, the earliest road was the best, and its continuous lines of massive kerb stones were very striking; the third road, which lay about four feet above the first, was of very poor quality, and probably dates from the middle or latter part of the fourth century.

The large house in the south-west quarter of the town, which was partly uncovered in 1906, has been completely explored, with the exception of a small portion at the north-east corner. Here, again, the remains belonged to several periods, but with the assistance of $\mathrm{Mr}$. W. $\mathrm{H}$. St. John Hope an intelligible plan has been made out, showing a building of considerable size, with returns at the east and west ends, enclosing what seem to have been a series of open courts. In its later stages the house had a northern and a southern corridor, and under a portion of the latter was a small pillared hypocaust, Plate I, fig. 1, while the remains of other hypocausts of a rougher description occurred in some of the western rooms.

Adjoining the north side of the house were the remains of an open court, in the centre of which, at an early period, there had been a fine cistern lined with opus signinum, but later this had been filled up and a wall built across it. Amongst the debris which had been used for this purpose was found a sculptured group of a lion and stag, which has attracted much attention, Plate II. The stag lies in a state of collapse, and the 
lion stands on its back, the whole group having apparently formed a fountain. The lion's open mouth is pierced at the back to admit a water-pipe, and probably the fountain played into the cistern in which the sculpture was found.

To the north of this court was a space which may possibly have been an open yard, but the remains discovered were in such confusion that it was scarcely possible to form any decided opinion. Still further up the slope was a range of chambers with a narrow platform or terrace on the south side. Beyond this line, on the brow of the hill, was a space in which practically no traces of foundations were discovered, but towards the northern limit of the reserved area were found several rubbish-pits, which produced terra sigillata and other pottery, a quantity of fragments of large amphorae, a small glass bottle of elegant design, and a bronze jug.

Much important work was also done in an adjoining field nearer the centre of the site. Here a broad paved street was found, showing the levels of three successive periods, the latest being probably of the latter part of the fourth century, possibly of the time of Theodosius. The excavations were mainly confined to the south side of this street, but as most of the buildings extended southwards into the next field a full investigation was not possible; one site, however, yielded important results. In the north-west corner of an earlier building were the remains of what had evidently been a shop for the sale of pottery. It had been destroyed by fire-to judge by the evidence of the coins found in it-not earlier than A.D. 340, and a large number of vessels were found in the burnt layer exactly as they had fallen when the shelves collapsed. The greater part of the stock had consisted of white montaria, and there was also a quantity of thin brown, grey, and drab ware; but the most important find consisted of the remains of a number of ressels of terra sigillata, many of which have been restored. These were mainly plain, straight-sided cups and dishes, which apart from other evidence would, on the strength of their shapes and the potters' marks, have been assigned to the second century ; but it seems fairly certain that they were exposed for sale in the shop in Corstopitum about the middle of the fourth century, 
$P L \pm T E, I I$.

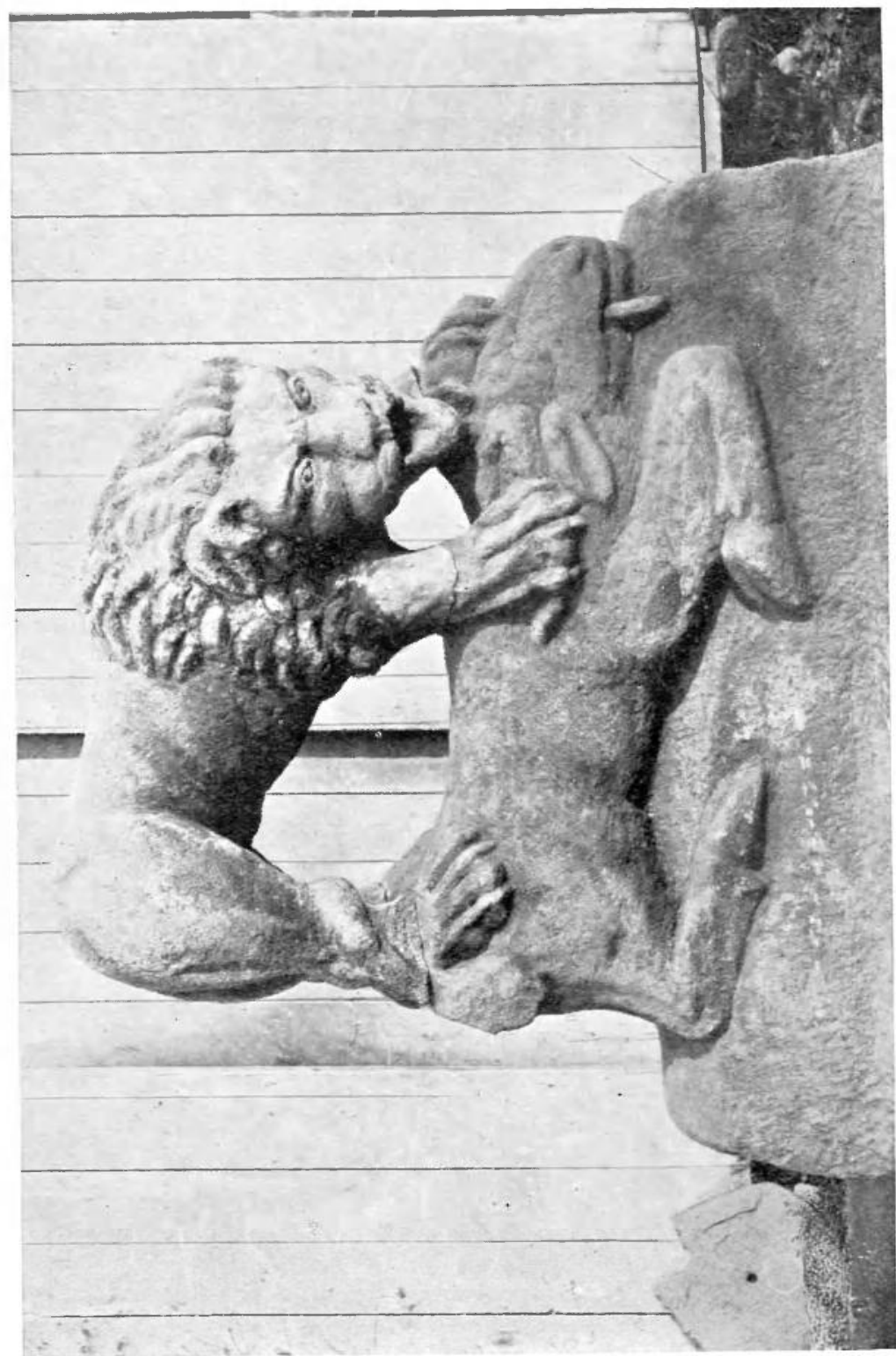




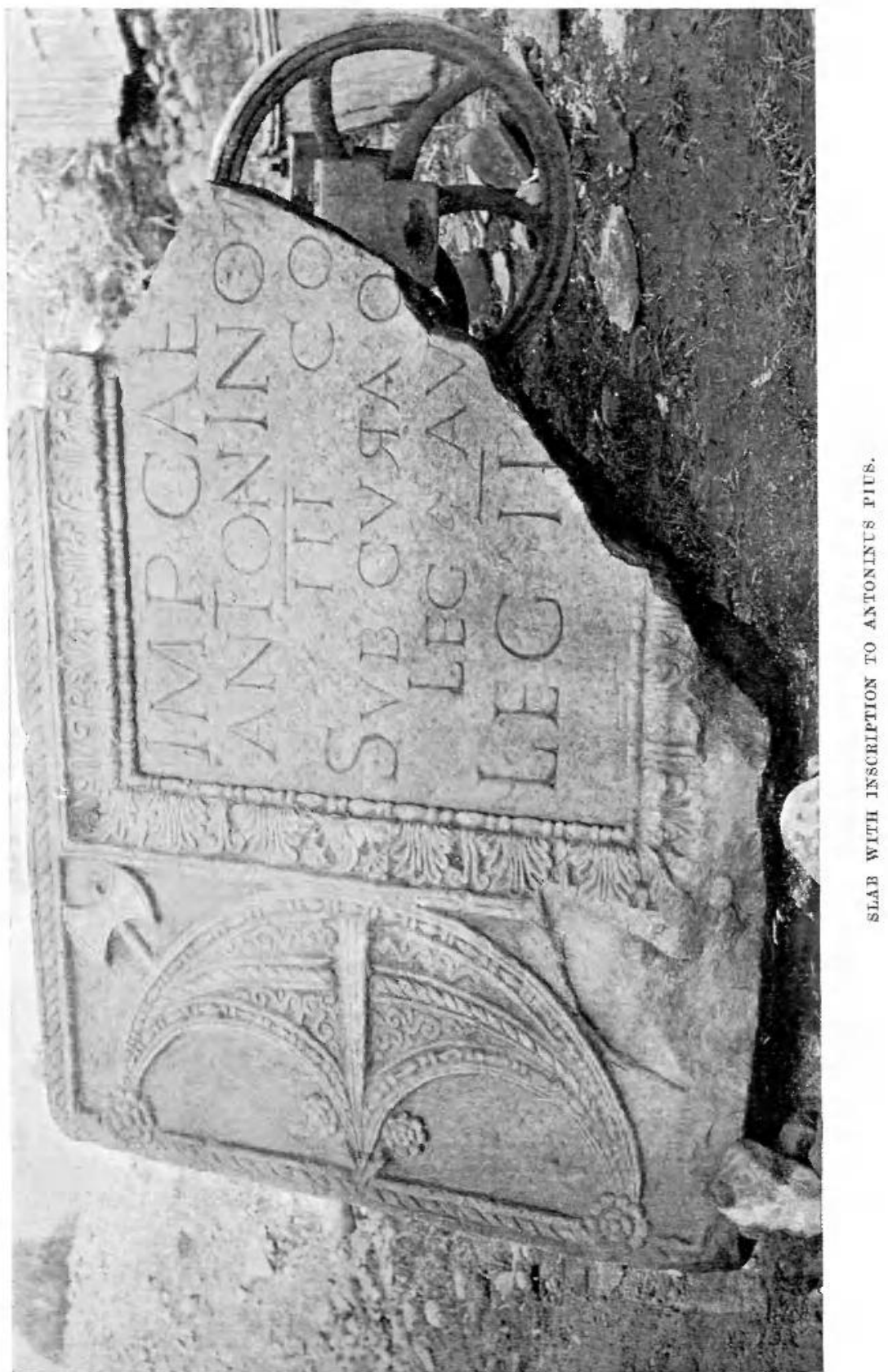


and the bearing of this fact on the received opinions as to the latest date of the manufacture of terra sigillata is likely to arouse much discussion.

On the north side of the street two sites were examined with important results. On one of these was found a large part of a finely carved slab, bearing an inscription to Antoninus Pius, set up in A.D. 140 by the Second Legion under Lollius Urbicus (Plate III). Close to this was a portion of another slab, on which was a representation of a legionary standard with the inscription VEXILLUS/LEG II AVG (Plate I, fig. 2). The site appears to have been occupied by an important building, which, it is "hoped, will be fully excavated this year. Immediately to the east were the remains of a structure of great interest, consisting of a podium of large dressed blocks. In front of this was a tank, from which, apparently, the inhabitants of the town had drawn their supplies of water, the slabs which formed the sides being irregularly scalloped, probably by the friction of the water vessels. The podium measures nineteen feet from east to west along the street front, and thirteen feet six inches from north to south, the northern corners being bevelled off above the foundation course. It appears to have been surrounded by a low screen of pilasters and carved stone panels, and at either side of the front there has been a substantial pedestal, probably for a statue. The structure may have supported a cistern for the supply of water to the tank, but more work is necessary before its purpose can be definitely determined. Near the north end were found fragments of a small pediment, which had been ornamented with winged Victories supporting a circular panel; the latter had borne the inscription LEG/XX. V.V./FECIT.

The excavations will be continued next July, the reserved area being a stretch of promising ground on the north side of the street in the upper field, and including the two last-mentioned sites. 
PLATE IF.

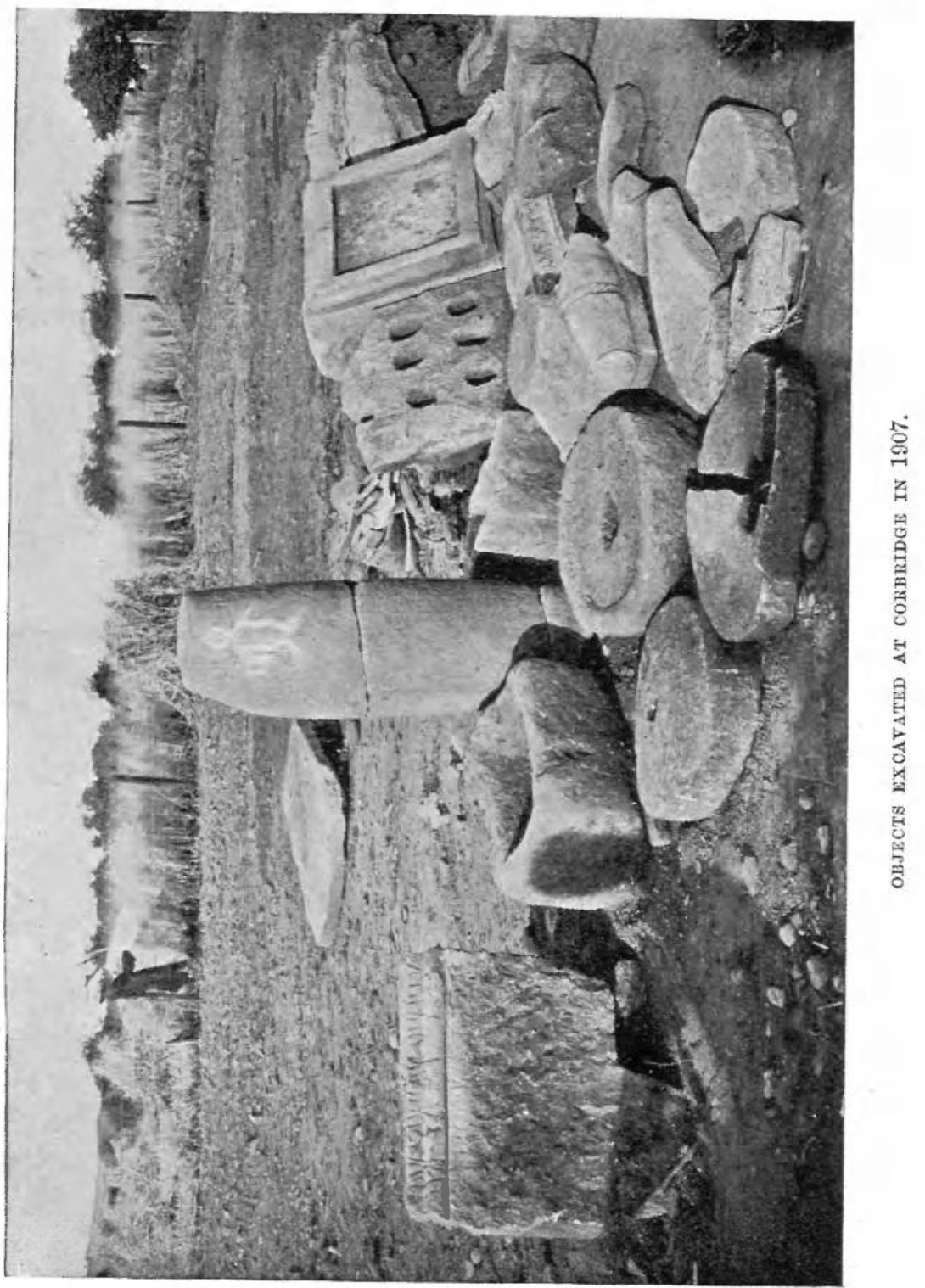

